(2) Open Access Full Text Article

\title{
Determination of the starting dose in the first-in- human clinical trials with monoclonal antibodies: a systematic review of papers published between 1990 and 2013
}

\author{
This article was published in the following Dove Press journal: \\ Drug Design, Development and Therapy \\ 8 December 2016 \\ Number of times this article has been viewed
}

\author{
Hoon Young Suh' \\ Carl C Peck ${ }^{2}$ \\ Kyung-Sang $\mathrm{Yu}^{\prime}$ \\ Howard Lee ${ }^{1,3}$ \\ 'Department of Clinical Pharmacology \\ and Therapeutics, College of \\ Medicine, Seoul National University \\ Hospital, Seoul, Korea; ${ }^{2}$ Department \\ of Bioengineering and Therapeutic \\ Sciences, School of Pharmacy, \\ University of California, San \\ Francisco, CA, USA; ${ }^{3}$ Department of \\ Transdisciplinary Studies, Graduate \\ School of Convergence Science and \\ Technology, Seoul National University, \\ Seoul, Korea
}

\begin{abstract}
A systematic review was performed to evaluate how the maximum recommended starting dose (MRSD) was determined in first-in-human (FIH) studies with monoclonal antibodies (mAbs). Factors associated with the choice of each MRSD determination method were also identified. PubMed was searched for FIH studies with mAbs published in English between January 1, 1990 and December 31, 2013, and the following information was extracted: MRSD determination method, publication year, therapeutic area, antibody type, safety factor, safety assessment results after the first dose, and number of dose escalation steps. Seventy-nine FIH studies with mAbs were identified, 49 of which clearly reported the MRSD determination method. The no observed adverse effects level (NOAEL)-based approach was the most frequently used method, whereas the model-based approach was the least commonly used method (34.7\% vs $16.3 \%)$. The minimal anticipated biological effect level (MABEL)- or minimum effective dose (MED)-based approach was used more frequently in 2011-2013 than in 1990-2007 (31.6\% vs 6.3\%, $P=0.036$ ), reflecting a slow, but steady acceptance of the European Medicines Agency's guidance on mitigating risks for FIH clinical trials (2007). The median safety factor was much lower for the MABEL- or MEDbased approach than for the other MRSD determination methods (10 vs 32.2-53). The number of dose escalation steps was not significantly different among the different MRSD determination methods. The MABEL-based approach appears to be safer and as efficient as the other MRSD determination methods for achieving the objectives of FIH studies with mAbs faster.
\end{abstract}

Keywords: MRSD determination method, starting dose in first-in-human study, first-in-human study with monoclonal antibody, MRSD, safety factor

\section{Introduction}

Determining the safe starting dose for humans is one of the most important steps before any new biopharmaceutical product under development can enter clinical testing for the first time. Ideally, the starting dose should be low not to cause any harm in humans, while it is expected to be not too low for efficacy, thereby reducing the number of patients exposed to ineffective doses in the first-in-human (FIH) clinical trials. ${ }^{1}$ The regulatory agencies such as the US Food and Drug Administration (FDA) and the European Medicines Agency (EMA) have published guidance documents to select the maximum recommended starting dose (MRSD) in the FIH study. ${ }^{2,3}$ The FDA guidance has been used in many FIH studies with new chemical entities of low-molecular weight, although it is also applicable to the FIH studies with biological agents. The emphasis in the FDA guidance is placed on the no observed adverse effects level (NOAEL) assessed in
Correspondence: Howard Lee Department of Clinical Pharmacology and Therapeutics, College of Medicine, Seoul National University Hospital,

I0I Daehak-ro, Jongno-gu, Seoul, Korea

Tel +82 236687602

Fax +8227429252

Email howardlee@snu.ac.kr
Drug Design, Development and Therapy 2016:10 4005-4016

4005

Dovepress f in

http://dx.doi.org/10.2147/DDDTS121520-

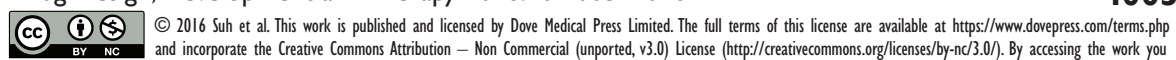

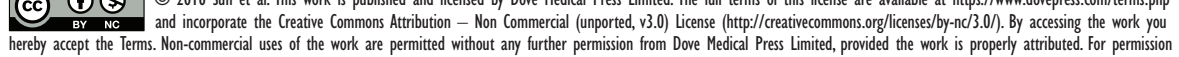

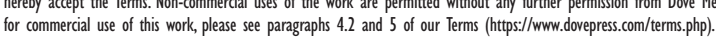


preclinical toxicology studies. ${ }^{2}$ The NOAEL is then converted into the human equivalence dose by applying an appropriate scaling factors to adjust for body surface area among different species. ${ }^{2}$ In contrast, the EMA guidance stresses the minimal anticipated biological effect level (MABEL) approach, in which all in vitro and in vivo information will be taken into consideration. ${ }^{3}$ The NOAEL- or the MABEL-derived human equivalence dose can be reduced further by applying the safety factor, a number by which the calculated human equivalence dose is divided to increase the assurance that the first dose will not cause toxicity in humans.

Since the 1980s, monoclonal antibodies (mAbs) have been actively incorporated into clinical medicine as a beneficial therapeutic option, particularly in oncology and immunology. ${ }^{4}$ However, protein-based drugs such as mAbs can have more uncertain safety profiles than those of chemistry-based drugs before an FIH study is conducted. For example, a severe life-threatening cytokine storm was developed in all the subjects who received the active drug in FIH study with TGN1412, a superagonist mAb against CD28, although a conservatively low starting dose was administered derived from the NOAEL (ie, a large safety factor of 160). ${ }^{5}$ This tragic incident highlighted the importance of and difficulties in selecting the safest maximum starting dose in FIH studies with mAbs. ${ }^{6}$ After the incident in the FIH study of TGN1412, several publications have proposed various ways to determine MRSD for FIH studies with biological agents. Many of these follow-up publications emphasized that MRSD for the FIH study with novel biological agents should be chosen after taking into account multiple points, for example, different endpoints, interspecies scaling, and safety factors. ${ }^{7,8}$ In support of this notion, a recent review found that the preclinical animal models and key toxicity parameters used to determine the starting dose for FIH studies with molecularly targeted agents in cancer patients were variable and heterogeneous. ${ }^{9}$ To the best of our knowledge, however, no investigation has reported how MRSD was determined in FIH studies with mAbs and which factors were associated with the choice of MRSD determination methods. Furthermore, the consequences of various MRSD determination methods have not been assessed, particularly in terms of safety and efficiency in achieving the objectives of FIH clinical trials. On the basis of this understanding, the objectives of the present study were 1) to evaluate MRSD determination methods employed in FIH studies with mAbs, 2) to identify factors associated with choosing one method over the others, and 3) to compare the safety and efficiency of each MRSD determination method. To achieve these objectives, we performed a systematic review of the papers that reported the results of FIH studies with mAbs from 1990 to 2013.

\section{Materials and methods}

\section{Literature search and selection of the FIH studies}

To construct a database for the FIH studies with mAbs, we searched PubMed using the combination of the following terms: clinical trial, phase I or phase 1, first-in-human or first-in-man, first-time-in-human or first-time-in-man, starting dose or initial dose, and $\mathrm{mAb}$. The literature search was complemented by an additional manual search of the references from the published papers and reviews focusing on mAbs. Eligible studies had to meet all of the following inclusion criteria: 1) the full text was available or there was at least a clear indication of how the MRSD was determined in the abstract or proceedings, 2) the text was written in English, and 3) the studies were published between January 1, 1990 and December 31, 2013.

\section{Classification of MRSD determination methods and data extraction}

If papers explicitly stated that the MRSD was determined based on a NOAEL, MABEL, minimum effective dose (MED), or pharmacologically active dose (PAD), they were classified as the respective dose- or level-based. Although a paper did not clearly indicate the MRSD determination method, it was also classified as NOAEL-, MABEL-, MED-, or PAD-based if the paper presented other information or supplemental data that enabled us to identify which method was used. For example, if a paper emphasized that no toxicity was found in the preclinical animal model up to a certain dose, which was used as the basis for determining the MRSD in humans, the method was NOAEL-based. Similarly, if the MRSD was determined from a dose identified in preclinical models that produced any or minimal pharmacological effect, the paper was classified as PAD- or MED-based, respectively. However, if animal pharmacokinetic (PK) data were the basis of MRSD determination or if a PK model was used to estimate the human PK parameters, which eventually resulted in the MRSD, the method was PK model-based. If the information about the receptor occupancy or other biomarkers was used to determine the MRSD, the method was pharmacodynamic (PD) model-based. If a PK-PD modeling approach was used to determine the MABEL, however, the paper was classified as MABEL-based. Because there were some similarities among MRSD determination methods, they were further grouped as follows: 1) MABEL- or MED-based 
(ie, MRSD was selected based on a dose associated with the minimal pharmacological effect) or 2) model-based (ie, PK, $\mathrm{PD}$, or PK-PD, in which MRSD was determined using a model-based approach).

We also collected the information about the factors that could have been associated with the choice of MRSD determination method: publication year, therapeutic area (ie, oncology, immunology, infection, and others), and antibody type (ie, murine, chimeric, humanized, fully human, and others). Because the MABEL-based approach was officially first introduced in the EMA guidance in 2007 , partly prompted by the TGN1412 incident, ${ }^{3}$ we categorized the publication year into three periods: before 2007 (ie, 1990-2007) and two 3-year periods after 2007 (ie, 2008-2010 and 2011-2013) to investigate the impact of the EMA guidance.

Furthermore, we extracted or derived the safety factor using the information available in the paper. In addition, we collected the safety result after the first dose and the number of dose escalation steps to evaluate the consequence of each MRSD determination method.

Two authors (HYS and HL) independently reviewed the papers and performed data extraction. The extracted data were then cross-checked for concurrence, and any differences were discussed until an agreement was reached.

\section{Statistical analysis}

Safety factor and MRSD determination method were summarized using descriptive statistics. The Fisher's exact test was performed to analyze whether MRSD determination method was significantly affected by the publication year, therapeutic area, and the type of mAbs. To test whether the median safety factor and the mean number of dose escalation steps were significantly different by MRSD determination method, the Kruskal-Wallis and the analysis of variance tests were performed, respectively. The SAS statistical software (version 9.4; SAS Institute, Inc., Cary, NC, USA) was used for the statistical analysis, and a two-tailed $P$-value $\leq 0.05$ was considered statistically significant.

\section{Results}

\section{Study identification}

The literature search identified 140 candidate FIH studies with mAbs, 61 of which were excluded because they did not meet the selection criteria: full text unavailable $(n=58)$ or not in English $(n=1)$; published before January 1, 1990 or after December 31, $2013(n=2)$. Hence, a total of 79 FIH studies were included in the final study database (Table S1). Overall, the majority of FIH studies with mAbs were performed in oncology $(n=41,51.9 \%)$, followed by immunology $(n=14$, $17.7 \%)$ and infection $(n=10,12.7 \%)$. The number of FIH studies with fully human antibodies and humanized antibodies has drastically increased since the early 2000s, whereas the number of FIH studies with murine or chimeric antibodies remained steadily low during the entire period (Figure 1).

\section{MRSD determination method}

Of 79 FIH studies with mAbs included in the study database, 49 studies $(62.0 \%)$ clearly indicated how the MRSD was

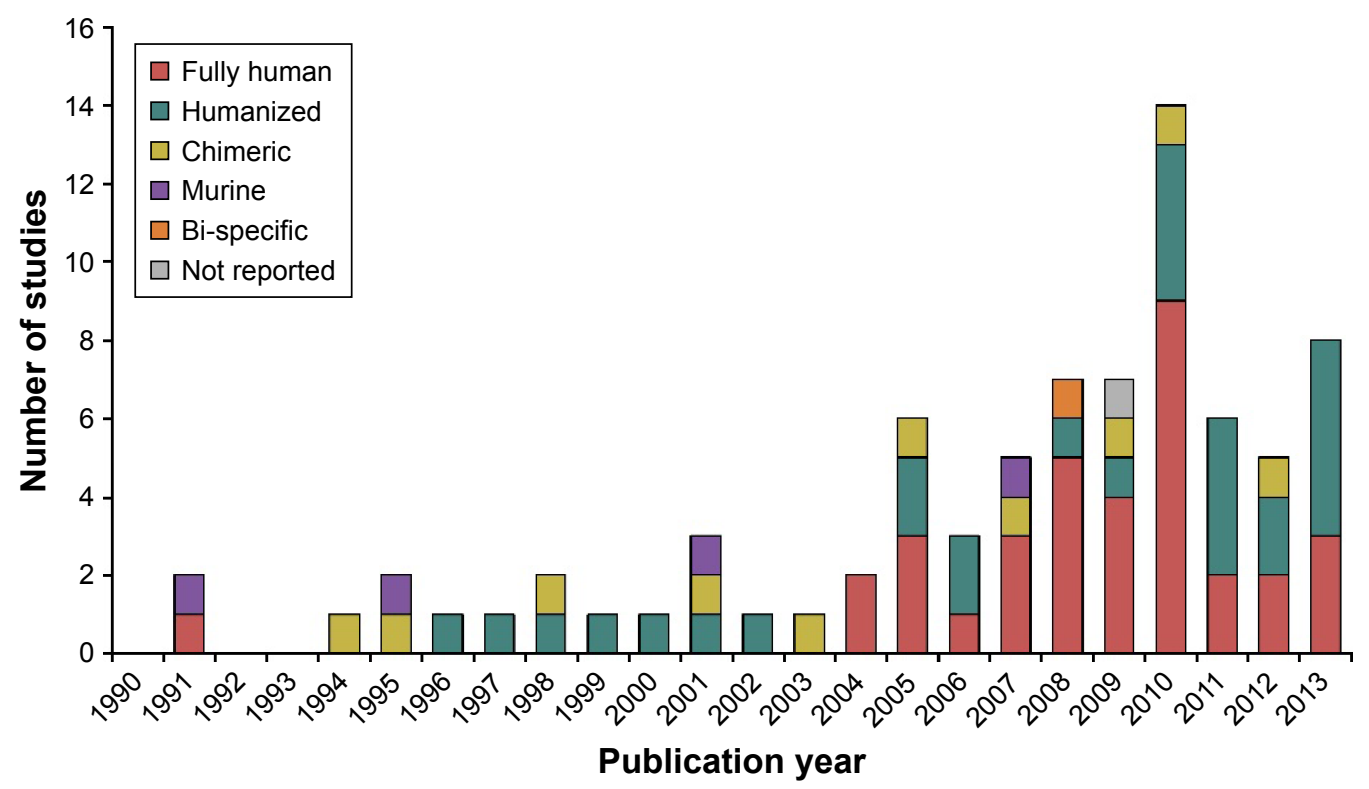

Figure I Types of monoclonal antibodies used in the first-in-human studies by publication year (1990-20I3). 
determined, whereas the remaining 30 studies (38.0\%) did not report the MRSD determination method (Figure 2). Of the 49 studies that reported the MRSD determination method, more than one-third used the NOAEL-based approach $(n=17$, $34.7 \%)$, followed by the PAD-based approach $(n=13,26.5 \%)$ and the MABEL- or MED-based approach ( $\mathrm{n}=11,22.4 \%)$. The model-based approach was the least common method $(n=8,16.3 \%)$.

\section{Factors associated with the choice of MRSD determination method}

The more recent the publications were the more frequently they reported which method was used to determine the MRSD. Almost 90\% of the studies published from 2011 to 2013 clearly indicated which method was used to determine the MRSD, whereas only half of the studies published before 2007 did (Table 1). The MABEL- or MED-based approach was used more frequently in 2011-2013 than in 1990-2007 (31.6\% vs 6.3\%, Table 1). Notably, the MABEL-based approach was not used until 2005 (Table S1; Figure 3). In contrast, the proportions of the other MRSD determination methods, particularly the model-based approach, did not appear to change much over the entire period of 1990-2013. Collectively, MRSD determination method varied significantly by publication year $(P=0.036$, Table 1$)$,

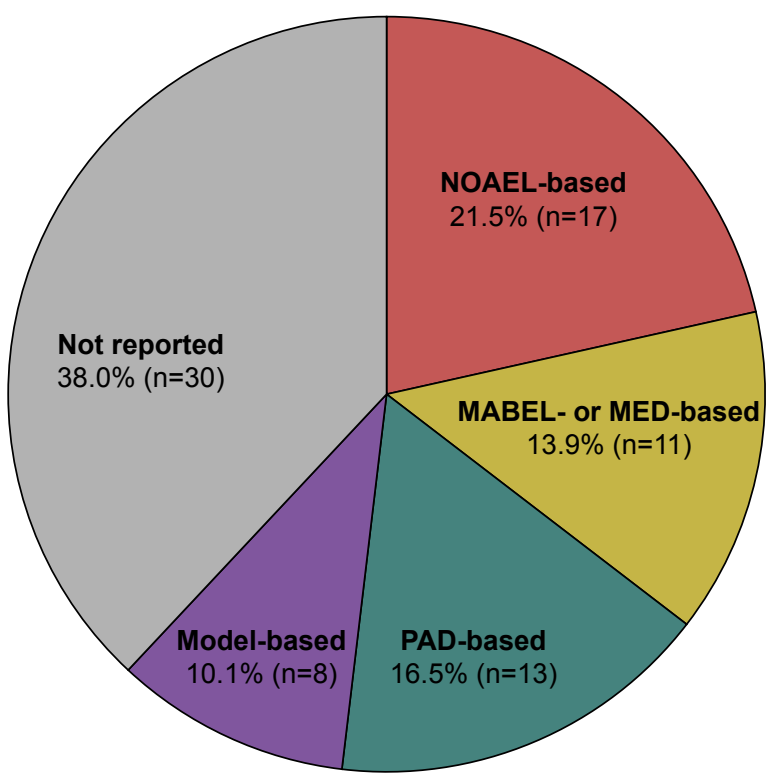

Figure 2 Overall proportion of the MRSD determination method in the first-inhuman studies with monoclonal antibodies.

Note: The model-based methods included PK model-based, PD model-based, and PK-PD model-based approaches.

Abbreviations: MABEL, minimal anticipated biological effect level; MED, minimum effective dose; MRSD, maximum recommended starting dose; NOAEL, no observed adverse effects level; PAD, pharmacologically active dose; PD, pharmacodynamics; PK, pharmacokinetic. whereas therapeutic area or antibody type was not significantly associated with the choice of MRSD determination method ( $P=0.995$ and 0.982 , respectively, Table 1$)$.

\section{Safety factor and consequence of MRSD determination method}

The median safety factor was numerically much lower for the MABEL- or MED-based approach than for the other approaches, although this difference failed to reach statistical significance (10 vs 32.2-53, $P=0.416$, Table 2 ). Fourteen studies $(17.7 \%)$ indicated that the first dose was safe, in which the MRSD was determined by the NOAEL-based $(n=6)$ and the MABEL- or MED-based approaches $(n=6)$. Only one study reported the first dose was not safe, in which the NOAEL was the basis for MRSD determination. The mean number of dose escalation steps was comparable among the different MRSD determination methods ( $P=0.177$, Figure 4$)$.

\section{Discussion}

We have found that the NOAEL-based approach was still the most commonly used MRSD determination method for FIH studies with mAbs, while the model-based approach was used far less frequently. Our results showed that more than one-third of the FIH studies employed the NOAEL-based approach, which was double the number of studies using the model-based approach (34.7\% vs $16.3 \%$, Figure 2$)$. This trend was rather disappointing, given that the usefulness of the model-based approach has been repeatedly emphasized in determining the MRSD. ${ }^{10-13}$ For example, a PK-PD model derived from cynomolgus monkeys enabled choosing $0.01 \mathrm{mg} / \mathrm{kg}$ as the MRSD for the FIH study with TRC105, an antibody with antiangiogenic effect to solid tumors. On the basis of the PK-PD model, the MRSD would successfully result in concentrations above the dissociation constant for the antibody, leading to a pharmacologic effect in humans. ${ }^{14}$ However, the infrequent use of the model-based approach to determine the MRSD can be attributed to the fact that animal data may not be available in sufficient detail to construct a model at the time of the FIH studies with mAbs. ${ }^{2,11,15}$ Furthermore, concerns about interspecies differences in bioavailability and metabolism could be another factor that has prevented the model-based approach from being applied more frequently in FIH studies with mAbs. ${ }^{16}$

Our results also showed that publication year was significantly associated with the choice of MRSD determination method, which was demonstrated in two ways. First, the proportion of FIH studies not reporting the MRSD determination method fell sharply to $10.5 \%$ in $2011-2013$ 
Table I Publication year, therapeutic area, and antibody type by MRSD determination method

\begin{tabular}{|c|c|c|c|c|c|c|c|}
\hline Factor & $\begin{array}{l}\text { NOAEL-based } \\
\text { approach }\end{array}$ & $\begin{array}{l}\text { MABEL- or MED- } \\
\text { based approach }\end{array}$ & $\begin{array}{l}\text { PAD-based } \\
\text { approach }\end{array}$ & $\begin{array}{l}\text { Model-based } \\
\text { approach* }\end{array}$ & $\begin{array}{l}\text { Not } \\
\text { reported }\end{array}$ & Total & P-value \\
\hline Publication year & & & & & & & $<0.05$ \\
\hline $1990-2007$ & $4(12.5 \%)$ & $2(6.2 \%)$ & 7 (21.9\%) & $3(9.4 \%)$ & 16 (50.0\%) & 32 (40.5\%) & \\
\hline $2008-2010$ & 8 (28.6\%) & $3(10.7 \%)$ & $2(7.1 \%)$ & $3(10.7 \%)$ & 12 (42.9\%) & 28 (35.4\%) & \\
\hline $2011-2013$ & $5(26.3 \%)$ & $6(31.6 \%)$ & 4 (2।.I\%) & $2(10.5 \%)$ & $2(10.5 \%)$ & 19 (24.1\%) & \\
\hline Therapeutic area & & & & & & & 0.995 \\
\hline Oncology & 9 (21.9\%) & $4(9.8 \%)$ & $8(19.5 \%)$ & $5(12.2 \%)$ & 15 (36.6\%) & $4 \mathrm{I}(51.9 \%)$ & \\
\hline Immunology & $3(21.4 \%)$ & $3(21.4 \%)$ & I (7.l\%) & I (7.I\%) & $6(43.0 \%)$ & 14 (I7.7\%) & \\
\hline Infection & $2(20.0 \%)$ & I (I0.0\%) & $2(20.0 \%)$ & I (I0.0\%) & $4(40.0 \%)$ & 10 (12.7\%) & \\
\hline Others & 3 (21.4\%) & $3(21.4 \%)$ & $2(14.3 \%)$ & I (7.I\%) & 5 (35.8\%) & 14 (I7.7\%) & \\
\hline Antibody type & & & & & & & 0.982 \\
\hline Murine & $0(0.0 \%)$ & I (25.0\%) & I (25.0\%) & I (25.0\%) & I (25.0\%) & $4(5.1 \%)$ & \\
\hline Chimeric & I (10.0\%) & I (10.0\%) & $2(20.0 \%)$ & I (I0.0\%) & $5(50.0 \%)$ & $10(12.7 \%)$ & \\
\hline Humanized & 6 (21.4\%) & $4(14.3 \%)$ & $4(14.3 \%)$ & $2(7.1 \%)$ & $12(43.0 \%)$ & 28 (35.4\%) & \\
\hline Fully human & 9 (25.7\%) & 5 (I4.3\%) & $6(17.2 \%)$ & 4 (II.4\%) & II (3I.4\%) & 35 (44.3\%) & \\
\hline Others & I (50.0\%) & $0(0.0 \%)$ & $0(0.0 \%)$ & $0(0.0 \%)$ & I (50.0\%) & $2(2.5 \%)$ & \\
\hline Total & 17 (2I.5\%) & II (I3.9\%) & I3 (I6.5\%) & $8(10.1 \%)$ & 30 (38.0\%) & 79 (100\%) & \\
\hline
\end{tabular}

Notes: The row percent is shown except for the total, in which the column percent is displayed. *The model-based methods included the PK model-based, PD model-based, and PK-PD model-based approaches. "P-values from Fisher's exact test.

Abbreviations: MABEL, minimal anticipated biological effect level; MED, minimum effective dose; MRSD, maximum recommended starting dose; NOAEL, no observed adverse effects level; PAD, pharmacologically active dose; PD, pharmacodynamic; PK, pharmacokinetic.

from $42.9 \%$ in $2008-2010$ and $50.0 \%$ in 1990-2007 (Table 1; Figure 3). It is encouraging that more FIH studies started reporting the MRSD determination method because this not only indicates increased transparency, but also it may allow for evaluating whether a certain type of MRSD determination method was useful or not in a particular study setting. Second, the MABEL- or MED-based approaches were more frequently used in 2011-2013 (31.6\%) than in 1990-2007
(6.2\%) and 2008-2010 (10.7\%, Table 1). In particular, the first MABEL-based FIH study with $\mathrm{mAb}$ was published in 2005, followed by another in 2007 and six during 2010-2013 (Table S1). This sharp increase during the latest period certainly reflects the impact of the tragic TGN1412 incident and the EMA guidance that followed the incident, which strongly recommended the use of the MABEL-based approach to determine MRSD. ${ }^{8,17}$ This trend is expected to continue in

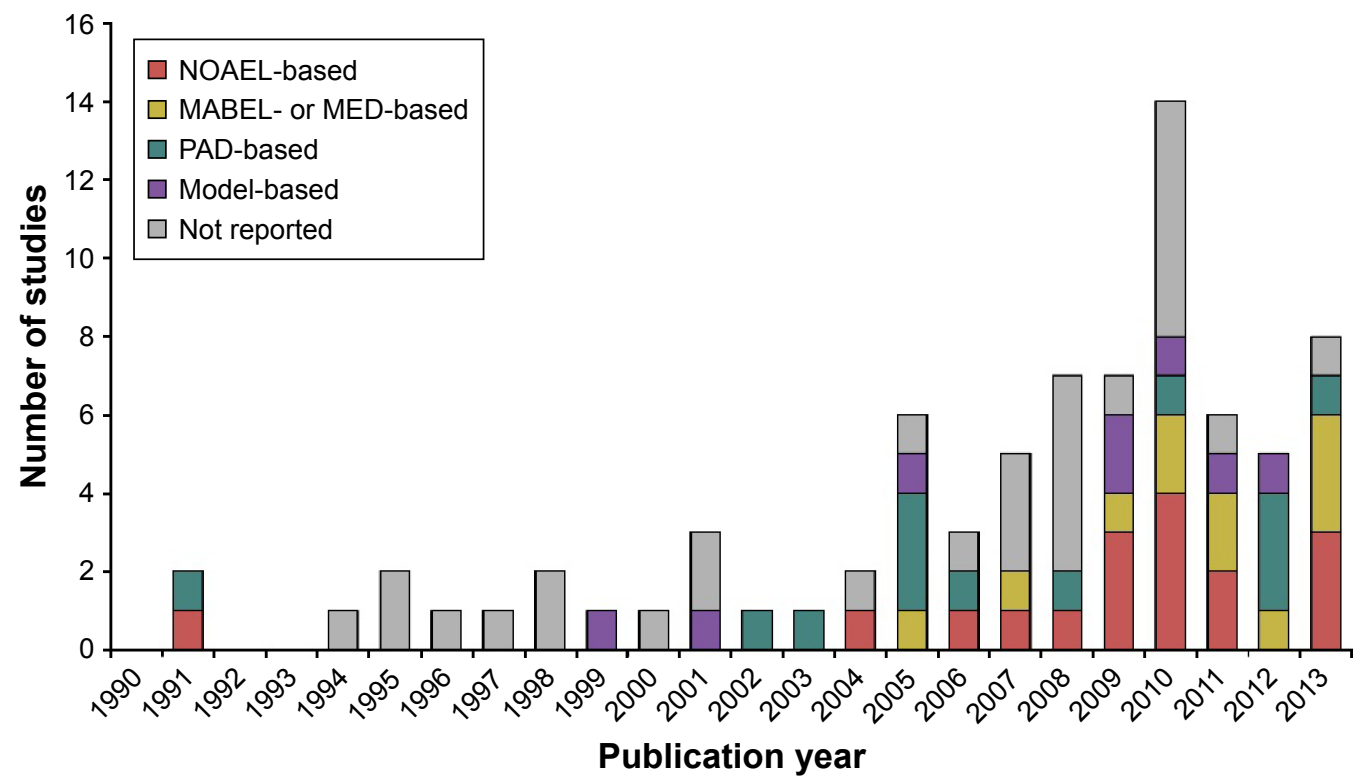

Figure 3 Yearly trend of the MRSD determination methods in the first-in-human studies with monoclonal antibodies (1990-2013).

Note: The model-based methods included the PK model-based, PD model-based, and PK-PD model-based approaches.

Abbreviations: MABEL, minimal anticipated biological effect level; MED, minimum effective dose; MRSD, maximum recommended starting dose; NOAEL, no observed adverse effects level; PAD, pharmacologically active dose; PD, pharmacodynamics; PK, pharmacokinetic. 
Table 2 Safety factors by MRSD determination method

\begin{tabular}{llllll}
\hline Factor & $\begin{array}{l}\text { NOAEL-based } \\
\text { approach }(\mathbf{n}=\mathbf{1 4})\end{array}$ & $\begin{array}{l}\text { MABEL- or MED- } \\
\text { based approach }(\mathbf{n}=\mathbf{8})\end{array}$ & $\begin{array}{l}\text { PAD-based } \\
\text { approach }(\mathbf{n}=\mathbf{3})\end{array}$ & $\begin{array}{l}\text { Model-based } \\
\text { approach }(\mathbf{n}=\mathbf{3})\end{array}$ \\
\hline Safety factor & $41.5(3.2-1,290)$ & $10(1-400)$ & $32.2(2-322)$ & $53(6.5-300)$ & 0.416 \\
\hline
\end{tabular}

Notes: *P-value from Kruskal-Wallis test. ${ }^{*}$ The median (range) is presented. The model-based methods included the PK model-based, PD model-based, and PK-PD modelbased approaches.

Abbreviations: MABEL, minimal anticipated biological effect level; MED, minimum effective dose; MRSD, maximum recommended starting dose; NOAEL, no observed adverse effects level; PAD, pharmacologically active dose; PD, pharmacodynamics; PK, pharmacokinetic.

the future given the heightened concern about the potential safety issues of biological agents including mAbs. However, the MABEL-based approach requires extensive knowledge regarding the pharmacological mechanisms and their integration, preferably via PK-PD modeling. ${ }^{10,18}$

The present study indicates that the safety factor varied widely by MRSD determination method. Namely, the MABEL- or MED-based approaches had much smaller median values of safety factor than the other MRSD determination methods (Table 2). The safety factor accounts for uncertainties such as potential interspecies differences and thereby serves as an additional means of assuring that toxicity dose not develop in humans at the first dose in FIH studies. ${ }^{19}$ Therefore, smaller safety factors indicated greater confidence for human safety at the time of FIH studies. ${ }^{2}$ The MABELbased approach always results in a smaller human equivalence

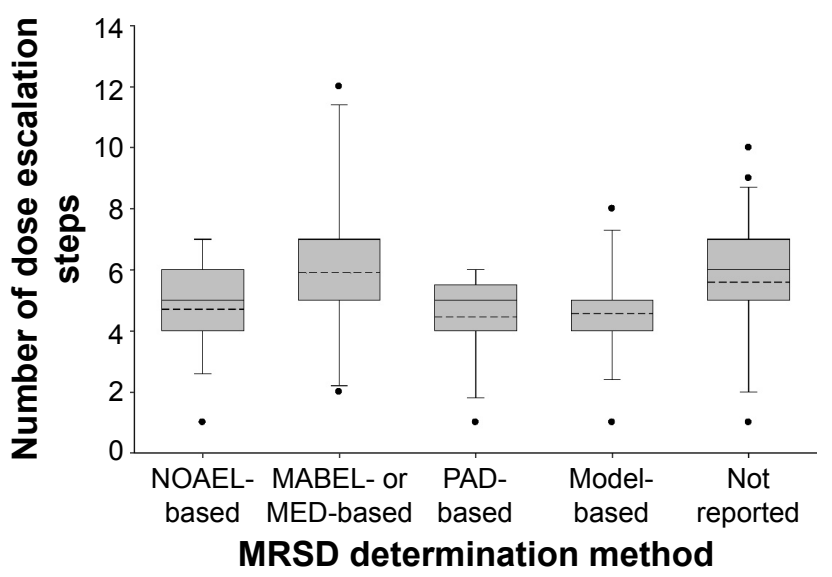

Figure 4 Number of dose escalation steps by the MRSD determination method in the first-in-human studies with monoclonal antibodies.

Notes: The line across each box, the top edge, and the bottom edge represent the median (solid line), the mean (short dash), the first quartile, and the third quartile, respectively (for the MABEL- or MED-, PAD-, and model-based approaches, the median values were the same as the first quartile values). The horizontal lines connected to the whiskers extending from the box denote the minimum and maximum values, respectively. The filled circles $(\bullet)$ indicate outliers, which are defined as either values less than the first quartile minus 1.5 times the interquartile range or values greater than the third quartile plus 1.5 times interquartile range. The model-based methods included the PK model-based, PD model-based, and PK-PD model-based approaches.

Abbreviations: MABEL, minimal anticipated biological effect level; MED, minimum effective dose; MRSD, maximum recommended starting dose; NOAEL, no observed adverse effects level; PAD, pharmacologically active dose; PD, pharmacodynamics; $\mathrm{PK}$, pharmacokinetic. dose than the other MRSD determination methods, particularly the NOAEL-based approach. ${ }^{20,21}$ Therefore, the safety factor tends to be smaller with the MABEL-based approach than with the other methods, as shown in our results.

Although the MABEL-based approach came up with an MRSD lower than those derived by the other approaches, the average number of dose escalation steps was similar (Figure 4). Fewer dose escalation steps indicated more efficient FIH studies. Therefore, the MABEL-based approach did not appear to be inferior to the other MRSD determination methods. Furthermore, more than half $(6 / 11=54.5 \%)$ of the papers that employed the MABEL-based approach explicitly indicated that the first dose was safe, which was almost $20 \%$ points higher than that with the NOAEL-based approach $(6 / 17=35.3 \%)$. Of course, this interpretation needs caution because $>80 \%$ of the papers did not explicitly mention about the safety results after the first dose.

The major limitation of the present study was the possibility of misclassifying MRSD determination method, particularly between the model- and MABEL-based approaches. Because the EMA guidance suggests that

all information available from $\mathrm{PK} / \mathrm{PD}$ data ... wherever pos-

sible ... should be integrated in a PK/PD modeling approach

for the determination of the MABEL (emphasis added)

some FIH studies classified as using the model-based approach had, in fact, used the MABEL-based approach. However, this possible misclassification was very unlikely to influence our final conclusion because only a small number of FIH studies ( $\mathrm{n}=8,10.1 \%$, Table 2$)$ were classified as modelbased. Another limitation was that the MRSD determination method was not identifiable in $30(=38 \%)$ FIH studies with $\mathrm{mAbs}$ because the authors did not report which method was used. Although our study database was constructed by a thorough literature search, further studies are warranted to circumvent this type of publication bias. ${ }^{22}$

\section{Conclusion}

We anticipate that the MABEL-based approach will be more frequently used in FIH studies with mAbs in the future, 
while the NOAEL-based approach is still likely to be the most commonly used method. The MABEL-based approach appears to be safer and as efficient as the other MRSD determination methods for achieving the objectives of FIH clinical trials faster. To the best of our knowledge, this is the first report showing the rapid acceptance of the MABEL-based approach in FIH studies with mAbs, reinforcing the impact of the EMA guidance. Our study can also illuminate the trends of the choice of MRSD determination methods, which may contribute to a safer design and conduct of FIH studies with mAbs in humans.

\section{Acknowledgments}

The authors thank the members of the Department of Clinical Pharmacology and Therapeutics, College of Medicine, Seoul National University Hospital. Particular thanks goes to Dr In-Jin Jang for providing helpful comments and suggestions. This work was partly supported by the Education and Research Encouragement Fund of Seoul National University Hospital.

\section{Disclosure}

The authors report no conflicts of interest in this work.

\section{References}

1. Ivy SP, Siu LL, Garrett-Mayer E, Rubinstein L. Approaches to phase 1 clinical trial design focused on safety, efficiency, and selected patient populations: a report from the clinical trial design task force of the national cancer institute investigational drug steering committee. Clin Cancer Res. 2010;16(6):1726-1736.

2. US Food and Drug Administration. Guidance for Industry: Estimating the Maximum Safe Starting Dose in Initial Clinical Trials for Therapeutics in Adult Healthy Volunteers. Rockville, MD: Food and Drug Administration; 2005. Available from: http://www.fda.gov/downloads/ drugs/guidances/ucm078932.pdf. Accessed July 6, 2005.

3. Committee for Medicinal Products for Human Use. Guideline on Strategies to Identify and Mitigate Risks for First-in-Human Clinical Trials with Investigational Medical Products. London, UK: European Medicines Agency; 2007: Available from: http://www.ema.europa. eu/docs/en_GB/document_library/Scientific_guideline/2009/09/ WC500002988.pdf. Accessed July 19, 2007.

4. Reichert JM, Rosensweig CJ, Faden LB, Dewitz MC. Monoclonal antibody successes in the clinic. Nat Biotech. 2005;23(9):1073-1078.

5. Stebbings R, Poole S, Thorpe R. Safety of biologics, lessons learnt from TGN1412. Curr Opin Biotechnol. 2009;20(6):673-677.
6. Suntharalingam G, Perry MR, Ward S, et al. Cytokine storm in a phase 1 trial of the anti-CD28 monoclonal antibody TGN1412. N Engl J Med. 2006;355(10):1018-1028.

7. Tibbitts J, Cavagnaro JA, Haller CA, Marafino B, Andrews PA, Sullivan JT. Practical approaches to dose selection for first-in-human clinical trials with novel biopharmaceuticals. Regul Toxicol Pharmacol. 2010;58(2):243-251.

8. Sharma V, McNeill JH. To scale or not to scale: the principles of dose extrapolation. B J Pharmacol. 2009;157(6):907-921.

9. Le Tourneau C, Stathis A, Vidal L, Moore MJ, Siu LL. Choice of starting dose for molecularly targeted agents evaluated in first-in-human phase I cancer clinical trials. J Clin Oncol. 2010;28(8):1401-1407.

10. Zou P, Yu Y, Zheng N, et al. Applications of human pharmacokinetic prediction in first-in-human dose estimation. AAPS J. 2012;14(2): 262-281.

11. Agoram BM. Use of pharmacokinetic/pharmacodynamic modelling for starting dose selection in first-in-human trials of high-risk biologics. Br J Clin Pharmacol. 2009;67(2):153-160.

12. Hansen AR, Cook N, Ricci MS, et al. Choice of starting dose for biopharmaceuticals in first-in-human phase I cancer clinical trials. Oncologist. 2015;20(6):653-659.

13. Tosi D, Laghzali Y, Vinches M, et al. Clinical development strategies and outcomes in first-in-human trials of monoclonal antibodies. J Clin Oncol. 2015;33(19):2158-2165.

14. Rosen LS, Hurwitz HI, Wong MK, et al. A phase I first-in-human study of TRC105 (anti-endoglin antibody) in patients with advanced cancer. Clin Cancer Res. 2012;18(17):4820-4829.

15. Agoram BM, Martin SW, van der Graaf PH. The role of mechanismbased pharmacokinetic-pharmacodynamic (PK-PD) modelling in translational research of biologics. Drug Discov Today. 2007;12(23): $1018-1024$.

16. Wang W, Wang E, Balthasar J. Monoclonal antibody pharmacokinetics and pharmacodynamics. Clin Pharmacol Ther. 2008;84(5):548-558.

17. Milton MN, Horvath CJ. The EMEA guideline on first-in-human clinical trials and its impact on pharmaceutical development. Toxicol Pathol.2009; 37(3):363-371.

18. Lowe PJ, Hijazi Y, Luttringer O, Yin H, Sarangapani R, Howard D. On the anticipation of the human dose in first-in-man trials from preclinical and prior clinical information in early drug development. Xenobiotica. 2007; 37(10-11):1331-1354.

19. Bokkers BG, Slob W. Deriving a data-based interspecies assessment factor using the NOAEL and the benchmark dose approach. Crit Rev Toxicol. 2007;37(5):355-373.

20. Zhao L, Ren T-h, Wang DD. Clinical pharmacology considerations in biologics development. Acta Pharmacol Sin. 2012;33(11): 1339-1347.

21. Muller PY, Milton M, Lloyd P, Sims J, Brennan FR. The minimum anticipated biological effect level (MABEL) for selection of first human dose in clinical trials with monoclonal antibodies. Curr Opin Biotechnol. 2009;20(6):722-729.

22. Easterbrook PJ, Gopalan R, Berlin J, Matthews DR. Publication bias in clinical research. Lancet. 1991;337(8746):867-872. 


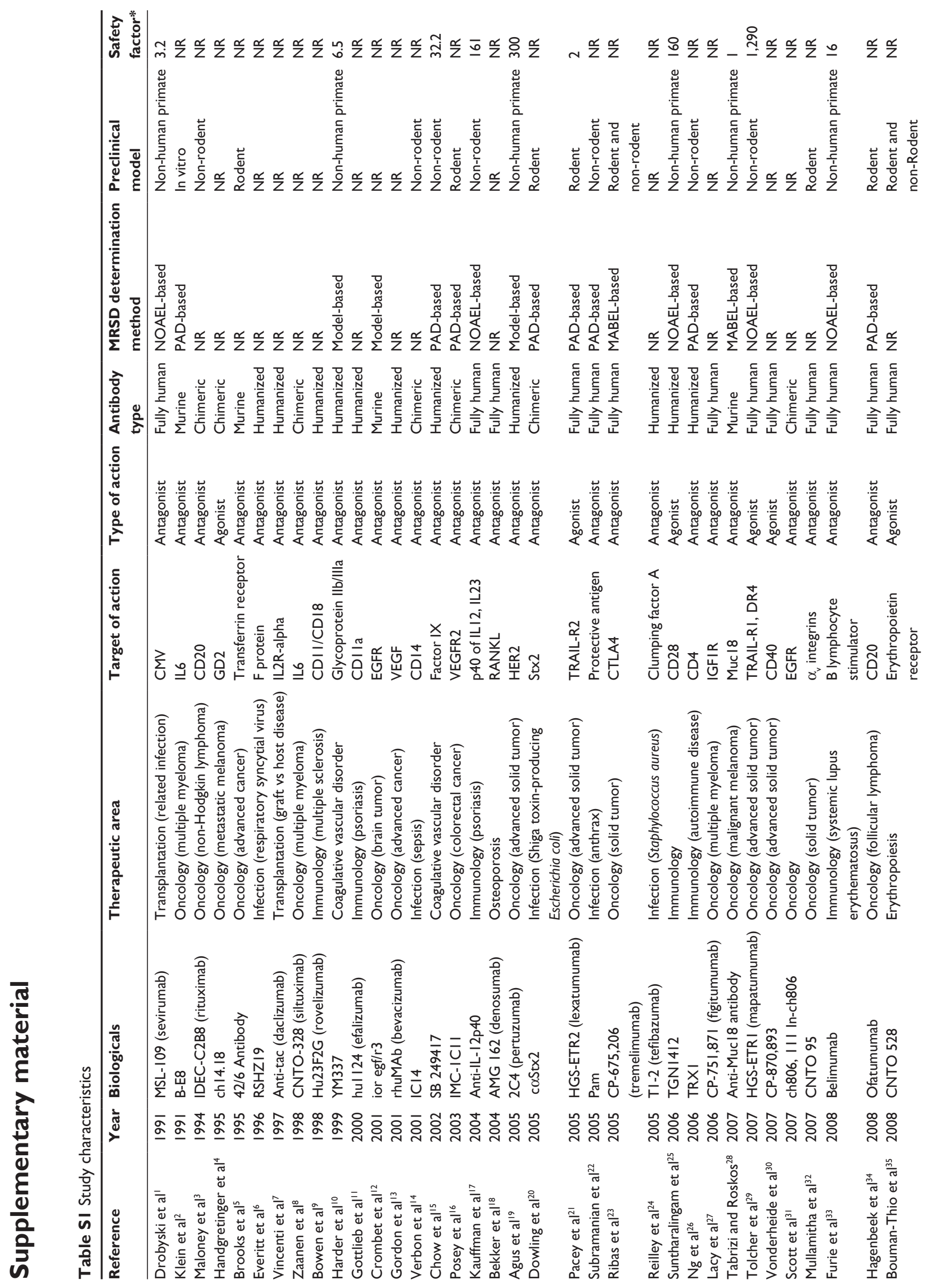




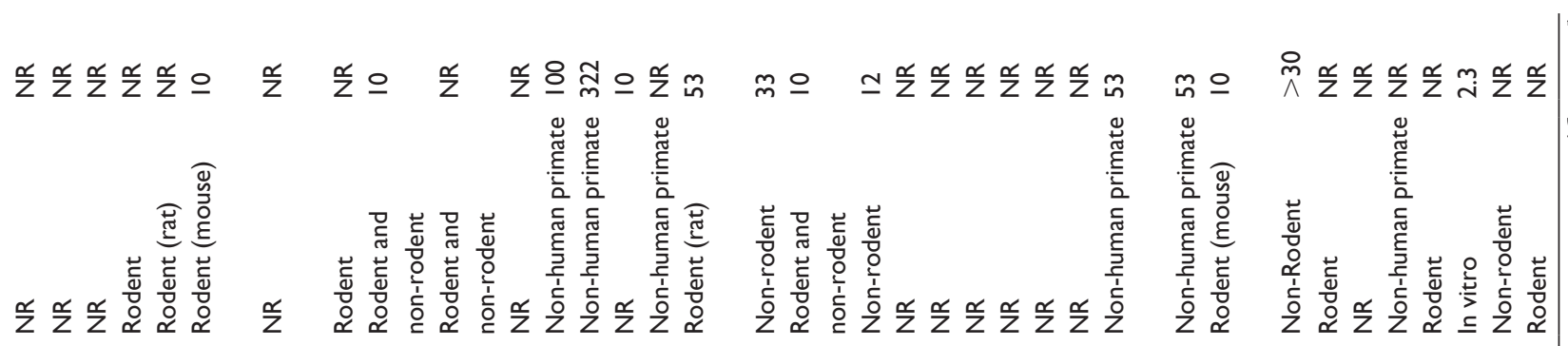

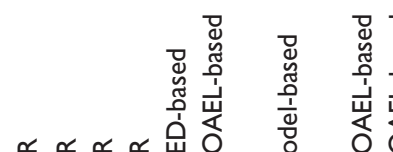

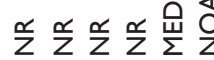

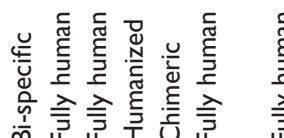

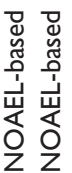

苞

윽

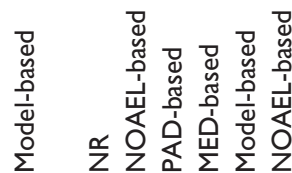

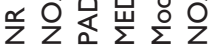

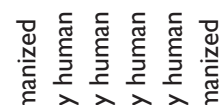

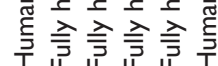

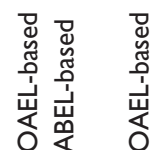

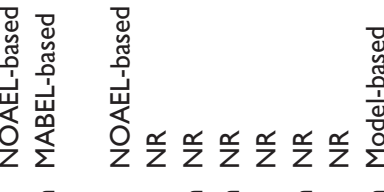

苋

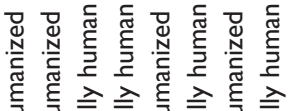

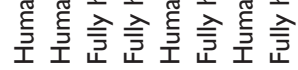

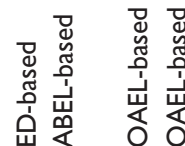

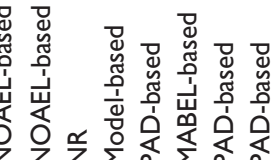

离
芯芯 总

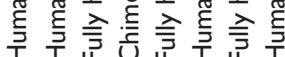

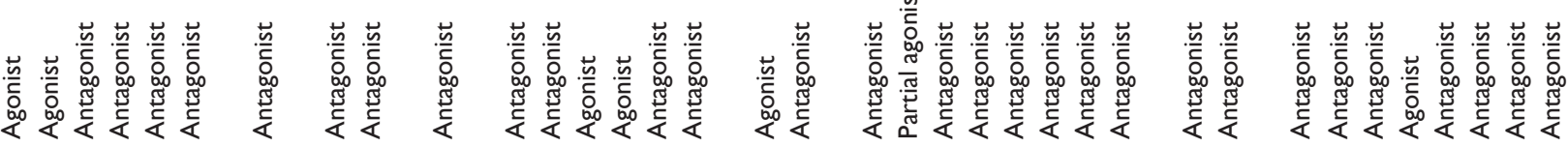

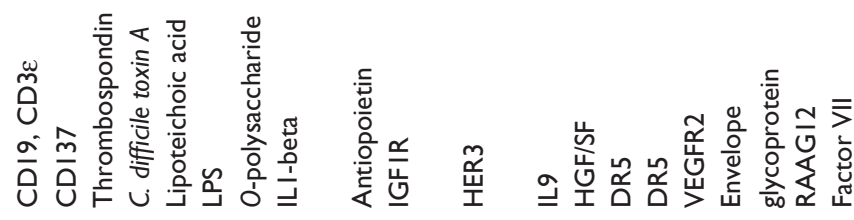

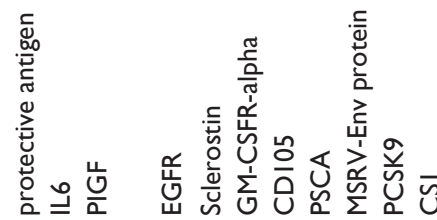

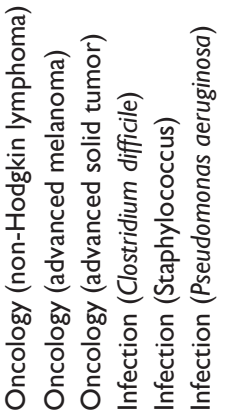

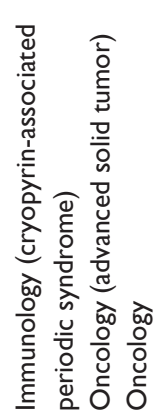

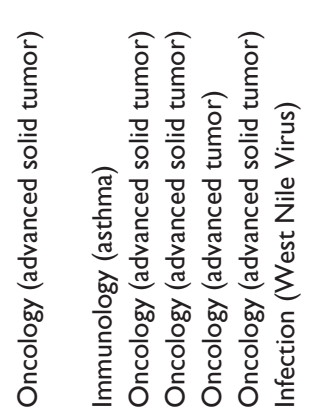
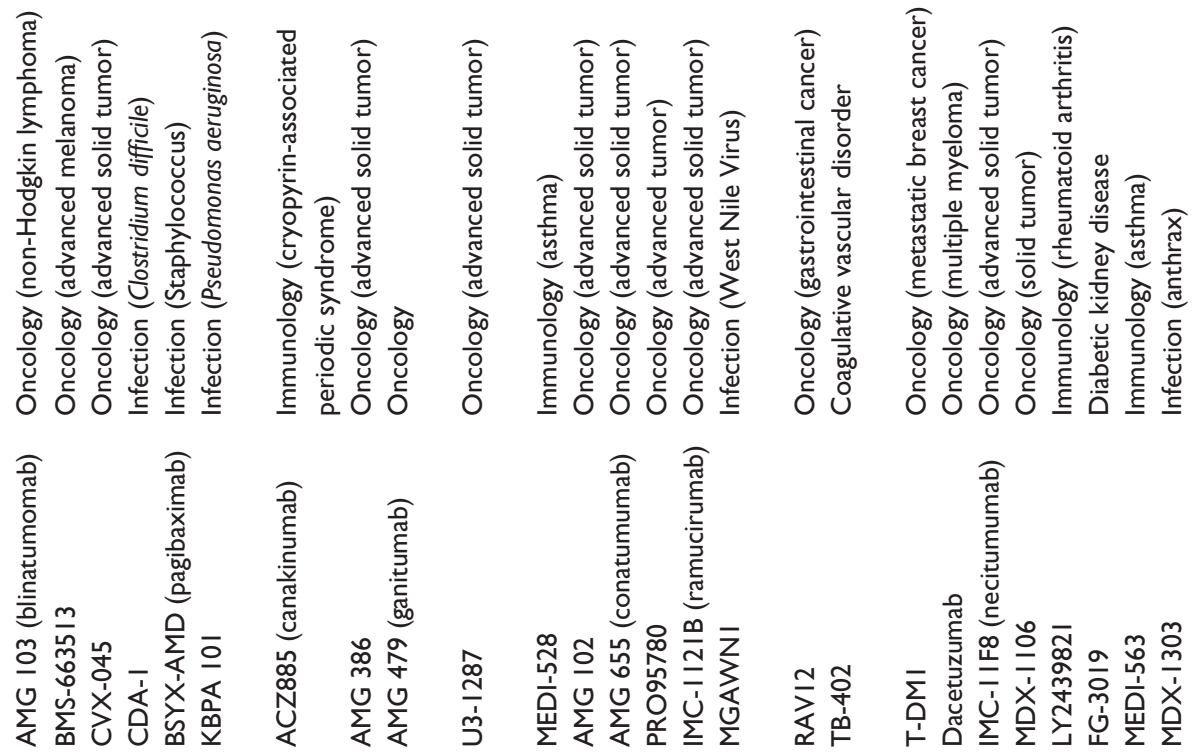

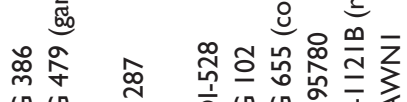

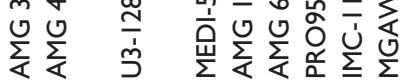

这站

里

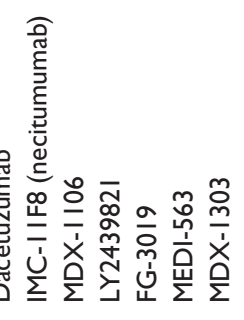

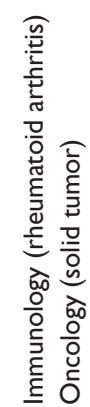

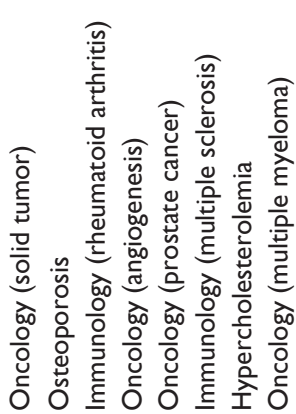

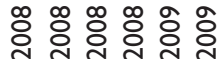

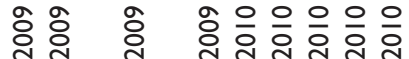

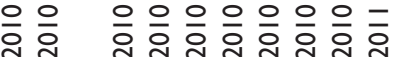
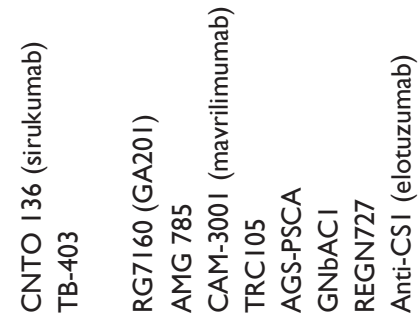

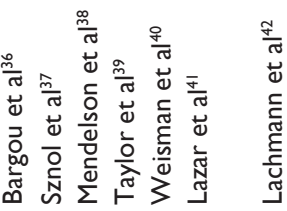
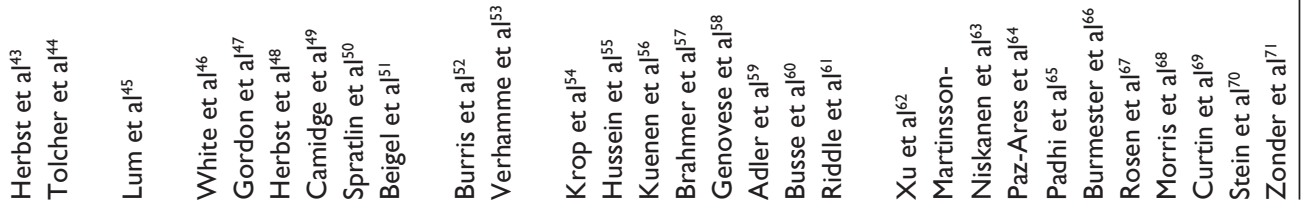


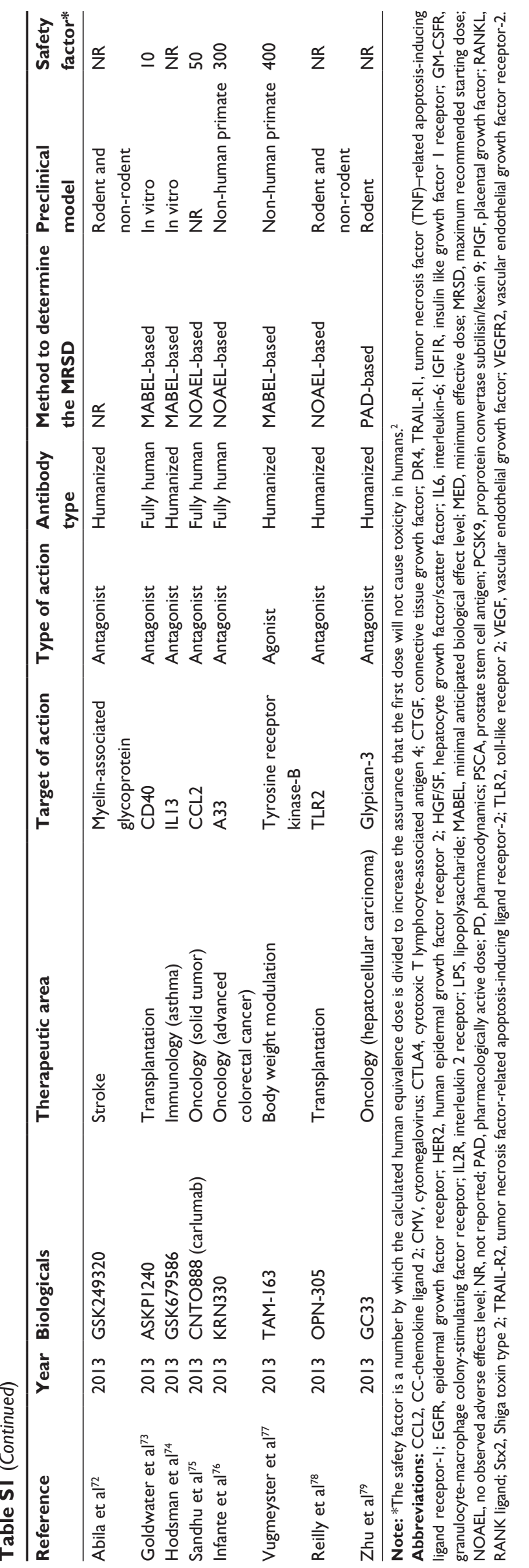

\section{References}

1. Drobyski WR, Gottlieb M, Carrigan D, et al. Phase I study of safety and pharmacokinetics of a human anticytomegalovirus monoclonal antibody in allogeneic bone marrow transplant recipients. Transplantation. 1991; 51(6):1190-1196.

2. Klein B, Wijdenes J, Zhang XG, et al. Murine anti-interleukin-6 monoclonal antibody therapy for a patient with plasma cell leukemia. Blood. 1991;78(5):1198-1204.

3. Maloney DG, Liles TM, Czerwinski DK, et al. Phase I clinical trial using escalating single-dose infusion of chimeric anti-CD20 monoclonal antibody (IDEC-C2B8) in patients with recurrent B-cell lymphoma. Blood. 1994;84(8):2457-2466.

4. Handgretinger R, Anderson K, Lang P, et al. A phase I study of human/ mouse chimeric antiganglioside GD2 antibody ch14. 18 in patients with neuroblastoma. Eur J Cancer. 1995;31(2):261-267.

5. Brooks D, Taylor C, Dos Santos B, et al. Phase Ia trial of murine immunoglobulin A antitransferrin receptor antibody 42/6. Clin Cancer Res. 1995; 1(11):1259-1265

6. Everitt DE, Davis CB, Thompson $\mathrm{K}$, et al. The pharmacokinetics, antigenicity, and fusion-inhibition activity of RSHZ19, a humanized monoclonal antibody to respiratory syncytial virus, in healthy volunteers. J Infect Dis. 1996;174(3):463-469.

7. Vincenti F, Lantz M, Birnbaum J, et al. A phase I trial of humanized anti-interleukin 2 receptor antibody in renal transplantation 1. Transplantation. 1997;63(1):33-38.

8. Zaanen V, Der Lelie V, Oers V. Chimaeric anti-interleukin 6 monoclonal antibodies in the treatment of advanced multiple myeloma: a phase I dose-escalating study. Br J Haematol. 1998;102(3):783-790.

9. Bowen JD, Petersdorf SH, Richards TL, et al. Phase I study of a humanized anti-CD11/CD18 monoclonal antibody in multiple sclerosis. Clin Pharmacol Ther. 1998;64(3):339-346.

10. Harder S, Kirchmaier CM, Krzywanek HJ, Westrup D, Bae JW, Breddin HK. Pharmacokinetics and pharmacodynamic effects of a new antibody glycoprotein IIb/IIIa inhibitor (YM337) in healthy subjects. Circulation. 1999;100(11):1175-1181.

11. Gottlieb A, Krueger JG, Bright R, et al. Effects of administration of a single dose of a humanized monoclonal antibody to CD11a on the immunobiology and clinical activity of psoriasis. J Am Acad Dermatol. 2000;42(3):428-435.

12. Crombet T, Torres O, Rodriguez V, et al. Phase I clinical evaluation of a neutralizing monoclonal antibody against epidermal growth factor receptor in advanced brain tumor patients: preliminary study. Hybridoma. 2001;20(2):131-136.

13. Gordon MS, Margolin K, Talpaz M, et al. Phase I safety and pharmacokinetic study of recombinant human anti-vascular endothelial growth factor in patients with advanced cancer. J Clin Oncol. 2001;19(3): 843-850.

14. Verbon A, Dekkers PE, ten Hove T, et al. IC14, an anti-CD14 antibody, inhibits endotoxin-mediated symptoms and inflammatory responses in humans. J Immunol. 2001;166(5):3599-3605.

15. Chow FS, Benincosa LJ, Sheth SB, et al. Pharmacokinetic and pharmacodynamic modeling of humanized anti-factor IX antibody (SB 249417) in humans. Clin Pharmacol Ther. 2002;71(4):235-245.

16. Posey JA, Ng TC, Yang B, et al. A phase I study of anti-kinase insert domain-containing receptor antibody, IMC-1C11, in patients with liver metastases from colorectal carcinoma. Clin Cancer Res. 2003;9(4): $1323-1332$

17. Kauffman CL, Aria N, Toichi E, et al. A phase I study evaluating the safety, pharmacokinetics, and clinical response of a human IL-12 p40 antibody in subjects with plaque psoriasis. J Invest Dermatol. 2004; 123(6):1037-1044

18. Bekker PJ, Holloway DL, Rasmussen AS, et al. A single-dose placebocontrolled study of AMG 162, a fully human monoclonal antibody to RANKL, in postmenopausal women. J Bone Miner Res. 2004;19(7): 1059-1066.

19. Agus DB, Gordon MS, Taylor C, et al. Phase I clinical study of pertuzumab, a novel HER dimerization inhibitor, in patients with advanced cancer. J Clin Oncol. 2005;23(11):2534-2543. 
20. Dowling TC, Chavaillaz PA, Young DG, et al. Phase 1 safety and pharmacokinetic study of chimeric murine-human monoclonal antibody $c \alpha$ Stx 2 administered intravenously to healthy adult volunteers. Antimicrob Agents Chemother. 2005;49(5):1808-1812.

21. Pacey S, Plummer R, Attard G, et al. Phase I and pharmacokinetic study of HGS-ETR2, a human monoclonal antibody to TRAIL R2, in patients with advanced solid malignancies. J Clin Oncol. 2005;23:3055.

22. Subramanian GM, Cronin PW, Poley G, et al. A phase 1 study of PAmAb, a fully human monoclonal antibody against Bacillus anthracis protective antigen, in healthy volunteers. Clin Infect Dis. 2005;41(1):12-20.

23. Ribas A, Camacho LH, Lopez-Berestein G, et al. Antitumor activity in melanoma and anti-self responses in a phase I trial with the anticytotoxic $\mathrm{T}$ lymphocyte-associated antigen 4 monoclonal antibody CP-675,206. J Clin Oncol. 2005;23(35):8968-8977.

24. Reilley S, Wenzel E, Reynolds L, Bennett B, Patti JM, Hetherington S. Open-label, dose escalation study of the safety and pharmacokinetic profile of tefibazumab in healthy volunteers. Antimicrob Agents Chemother. 2005;49(3):959-962.

25. Suntharalingam G, Perry MR, Ward S, et al. Cytokine storm in a phase 1 trial of the anti-CD28 monoclonal antibody TGN1412. N Engl J Med 2006;355(10):1018-1028.

26. Ng CM, Stefanich E, Anand BS, Fielder PJ, Vaickus L. Pharmacokinetics/pharmacodynamics of nondepleting anti-CD4 monoclonal antibody (TRX1) in healthy human volunteers. Pharm Res. 2006;23(1):95-103.

27. Lacy M, Alsina M, Melvin CL, et al. Phase 1 first-in-human dose escalation study of cp-751,871, a specific monoclonal antibody against the insulin like growth factor 1 receptor. J Clin Oncol. 2006;24:7609.

28. Tabrizi MA, Roskos LK. Preclinical and clinical safety of monoclonal antibodies. Drug Discov Today. 2007;12(13-14):540-547.

29. Tolcher AW, Mita M, Meropol NJ, et al. Phase I pharmacokinetic and biologic correlative study of mapatumumab, a fully human monoclonal antibody with agonist activity to tumor necrosis factor-related apoptosisinducing ligand receptor-1. J Clin Oncol. 2007;25(11):1390-1395.

30. Vonderheide RH, Flaherty KT, Khalil M, et al. Clinical activity and immune modulation in cancer patients treated with CP-870,893, a novel CD40 agonist monoclonal antibody. J Clin Oncol. 2007;25(7):876-883.

31. Scott AM, Lee FT, Tebbutt N, et al. A phase I clinical trial with monoclonal antibody ch806 targeting transitional state and mutant epidermal growth factor receptors. Proc Natl Acad Sci U S A. 2007;104(10): 4071-4076.

32. Mullamitha SA, Ton NC, Parker GJ, et al. Phase I evaluation of a fully human anti- $\alpha \mathrm{v}$ integrin monoclonal antibody (CNTO 95) in patients with advanced solid tumors. Clin Cancer Res. 2007;13(7):2128-2135.

33. Furie R, Stohl W, Ginzler EM, et al. Biologic activity and safety of belimumab, a neutralizing anti-B-lymphocyte stimulator (BLyS) monoclonal antibody: a phase I trial in patients with systemic lupus erythematosus. Arthritis Res Ther. 2008;10(5):R109.

34. Hagenbeek A, Gadeberg O, Johnson P, et al. First clinical use of ofatumumab, a novel fully human anti-CD20 monoclonal antibody in relapsed or refractory follicular lymphoma: results of a phase $1 / 2$ trial. Blood. 2008;111(12):5486-5495.

35. Bouman-Thio E, Franson K, Miller B, et al. A phase I, single and fractionated, ascending-dose study evaluating the safety, pharmacokinetics, pharmacodynamics, and immunogenicity of an erythropoietin mimetic antibody fusion protein (CNTO 528) in healthy male subjects. $J$ Clin Pharmacol. 2008;48(10):1197-1207.

36. Bargou R, Leo E, Zugmaier G, et al. Tumor regression in cancer patients by very low doses of a T cell-engaging antibody. Science. 2008;321(5891): 974-977.

37. Sznol M, Hodi F, Margolin K, et al. Phase I study of BMS-663513, a fully human anti-CD137 agonist monoclonal antibody, in patients (pts) with advanced cancer (CA). J Clin Oncol. 2008;26:3007.

38. Mendelson D, Dinolfo M, Cohen R, et al. First-in-human dose escalation safety and pharmacokinetic (PK) trial of a novel intravenous (IV) thrombospondin-1 (TSP-1) mimetic humanized monoclonal CovX Body (CVX-045) in patients (pts) with advanced solid tumors. $J$ Clin Oncol. 2008;26(Suppl 15):3524.
39. Taylor CP, Tummala S, Molrine D, et al. Open-label, dose escalation phase I study in healthy volunteers to evaluate the safety and pharmacokinetics of a human monoclonal antibody to Clostridium difficile toxin A. Vaccine. 2008;26(27):3404-3409.

40. Weisman LE, Fischer GW, Thackray HM, et al. Safety and pharmacokinetics of a chimerized anti-lipoteichoic acid monoclonal antibody in healthy adults. Int Immunopharmacol. 2009;9(5):639-644.

41. Lazar H, Horn MP, Zuercher AW, et al. Pharmacokinetics and safety profile of the human anti-Pseudomonas aeruginosa serotype $\mathrm{O} 11 \mathrm{immu}-$ noglobulin M monoclonal antibody KBPA-101 in healthy volunteers. Antimicrob Agents Chemother. 2009;53(8):3442-3446.

42. Lachmann HJ, Kone-Paut I, Kuemmerle-Deschner JB, et al. Use of canakinumab in the cryopyrin-associated periodic syndrome. $N$ Engl J Med. 2009;360(23):2416-2425.

43. Herbst RS, Hong D, Chap L, et al. Safety, pharmacokinetics, and antitumor activity of AMG 386, a selective angiopoietin inhibitor, in adult patients with advanced solid tumors. J Clin Oncol. 2009;27(21): $3557-3565$.

44. Tolcher AW, Sarantopoulos J, Patnaik A, et al. Phase I, pharmacokinetic, and pharmacodynamic study of AMG 479, a fully human monoclonal antibody to insulin-like growth factor receptor 1. J Clin Oncol. 2009;27(34):5800-5807.

45. Lum P, Ruixo JJP, Ogbagabriel S, et al. Abstract B167: identifying first in human (FIH) doses and schedule of U3-1287 (AMG 888), a fully human anti-HER3 mAb, based on preclinical pharmacokinetic (PK), pharmacodynamic (PD) and efficacy data. Mol Cancer Ther. 2009; 8(Suppl 12):B167.

46. White B, Leon F, White W, Robbie G. Two first-in-human, open-label, phase I dose-escalation safety trials of MEDI-528, a monoclonal antibody against interleukin-9, in healthy adult volunteers. Clin Ther. 2009;31(4):728-740.

47. Gordon MS, Sweeney CJ, Mendelson DS, et al. Safety, pharmacokinetics, and pharmacodynamics of AMG 102, a fully human hepatocyte growth factor-neutralizing monoclonal antibody, in a first-in-human study of patients with advanced solid tumors. Clin Cancer Res. 2010;16(2): 699-710.

48. Herbst RS, Kurzrock R, Hong DS, et al. A first-in-human study of conatumumab in adult patients with advanced solid tumors. Clin Cancer Res. 2010;16(23):5883-5891.

49. Camidge DR, Herbst RS, Gordon MS, et al. A phase I safety and pharmacokinetic study of the death receptor 5 agonistic antibody PRO95780 in patients with advanced malignancies. Clin Cancer Res. 2010;16(4): $1256-1263$.

50. Spratlin JL, Cohen RB, Eadens M, et al. Phase I pharmacologic and biologic study of ramucirumab (IMC-1121B), a fully human immunoglobulin G1 monoclonal antibody targeting the vascular endothelial growth factor receptor-2. J Clin Oncol. 2010;28(5):780-787.

51. Beigel JH, Nordstrom JL, Pillemer SR, et al. Safety and pharmacokinetics of single intravenous dose of MGAWN1, a novel monoclonal antibody to West Nile virus. Antimicrob Agents Chemother. 2010;54(6): 2431-2436.

52. Burris HA, Rosen LS, Rocha-Lima CM, et al. Phase 1 experience with an anti-glycotope monoclonal antibody, RAV12, in recurrent adenocarcinoma. Clin Cancer Res. 2010;16(5):1673-1681.

53. Verhamme P, Pakola S, Jensen TJ, et al. Tolerability and pharmacokinetics of TB-402 in healthy male volunteers. Clin Ther. 2010;32(6): $1205-1220$.

54. Krop IE, Beeram M, Modi S, et al. Phase I study of trastuzumab-DM1, an HER 2 antibody-drug conjugate, given every 3 weeks to patients with HER2-positive metastatic breast cancer. J Clin Oncol. 2010;28(16): 2698-2704.

55. Hussein M, Berenson JR, Niesvizky R, et al. A phase I multidose study of dacetuzumab (SGN-40; humanized anti-CD40 monoclonal antibody) in patients with multiple myeloma. Haematologica. 2010;95(5):845-848.

56. Kuenen B, Witteveen PO, Ruijter R, et al. A phase I pharmacologic study of necitumumab (IMC-11F8), a fully human IgG1 monoclonal antibody directed against EGFR in patients with advanced solid malignancies. Clin Cancer Res. 2010;16(6):1915-1923. 
57. Brahmer JR, Drake CG, Wollner I, et al. Phase I study of single-agent anti-programmed death-1 (MDX-1106) in refractory solid tumors: safety, clinical activity, pharmacodynamics, and immunologic correlates. J Clin Oncol. 2010;28(19):3167-3175.

58. Genovese MC, Van den Bosch F, Roberson S, et al. LY2439821, a humanized anti-interleukin-17 monoclonal antibody, in the treatment of patients with rheumatoid arthritis: a phase I randomized, double-blind, placebo-controlled, proof-of-concept study. Arthritis Rheum. 2010;62(4): 929-939.

59. Adler SG, Schwartz S, Williams ME, et al. Phase 1 study of anti-CTGF monoclonal antibody in patients with diabetes and microalbuminuria. Clin J Am Soc Nephrol. 2010;5(8):1420-1428.

60. Busse WW, Katial R, Gossage D, et al. Safety profile, pharmacokinetics, and biologic activity of MEDI-563, an anti-IL-5 receptor $\alpha$ antibody, in a phase I study of subjects with mild asthma. J Allergy Clin Immunol. 2010;125(6):1237-1244.

61. Riddle V, Leese P, Blanset D, Adamcio M, Meldorf M, Lowy I. Phase I study evaluating the safety and pharmacokinetics of MDX-1303, a fully human monoclonal antibody against Bacillus anthracis protective antigen, in healthy volunteers. Clin Vaccine Immunol. 2011;18(12): 2136-2142.

62. Xu Z, Bouman-Thio E, Comisar C, et al. Pharmacokinetics, pharmacodynamics and safety of a human anti-IL-6 monoclonal antibody (siruku$\mathrm{mab}$ ) in healthy subjects in a first-in-human study. Br J Clin Pharmacol. 2011;72(2):270-281.

63. Martinsson-Niskanen T, Riisbro R, Larsson L, et al. Monoclonal antibody TB-403: a first-in-human, phase I, double-blind, dose escalation study directed against placental growth factor in healthy male subjects. Clin Ther. 2011;33(9):1142-1149.

64. Paz-Ares LG, Gomez-Roca C, Delord JP, et al. Phase I pharmacokinetic and pharmacodynamic dose-escalation study of RG7160 (GA201), the first glycoengineered monoclonal antibody against the epidermal growth factor receptor, in patients with advanced solid tumors. J Clin Oncol. 2011;29(28):3783-3790.

65. Padhi D, Jang G, Stouch B, Fang L, Posvar E. Single-dose, placebocontrolled, randomized study of AMG 785, a sclerostin monoclonal antibody. J Bone Miner Res. 2011;26(1):19-26.

66. Burmester GR, Feist E, Sleeman MA, Wang B, White B, Magrini F. Mavrilimumab, a human monoclonal antibody targeting GM-CSF receptor-alpha, in subjects with rheumatoid arthritis: a randomised, doubleblind, placebo-controlled, phase I, first-in-human study. Ann Rheum Dis. 2011;70(9):1542-1549.

67. Rosen LS, Hurwitz HI, Wong MK, et al. A phase I first-in-human study of TRC105 (anti-endoglin antibody) in patients with advanced cancer. Clin Cancer Res. 2012;18(17):4820-4829.
68. Morris MJ, Eisenberger MA, Pili R, et al. A phase I/IIA study of AGS-PSCA for castration-resistant prostate cancer. Ann Oncol. 2012; 23(10):2714-2719.

69. Curtin F, Lang AB, Perron $\mathrm{H}$, et al. GNbAC1, a humanized monoclonal antibody against the envelope protein of multiple sclerosis-associated endogenous retrovirus: a first-in-humans randomized clinical study. Clin Ther. 2012;34(12):2268-2278.

70. Stein EA, Mellis S, Yancopoulos GD, et al. Effect of a monoclonal antibody to PCSK9 on LDL cholesterol. N Engl J Med. 2012;366(12): 1108-1118.

71. Zonder JA, Mohrbacher AF, Singhal S, et al. A phase 1, multicenter, open-label, dose escalation study of elotuzumab in patients with advanced multiple myeloma. Blood. 2012;120(3):552-559.

72. Abila B, Cunningham E, Simeoni M. First-time-in-human study with GSK249320, a myelin-associated glycoprotein inhibitor, in healthy volunteers. Clin Pharmacol Ther. 2013;93(2):163-169.

73. Goldwater R, Keirns J, Blahunka P, et al. A phase 1, randomized ascending single-dose study of antagonist anti-human CD40 ASKP1240 in healthy subjects. Am J Transplant. 2013;13(4):1040-1046.

74. Hodsman P, Ashman C, Cahn A, et al. A phase 1, randomized, placebocontrolled, dose-escalation study of an anti-IL-13 monoclonal antibody in healthy subjects and mild asthmatics. Br J Clin Pharmacol. 2013; 75(1):118-128.

75. Sandhu SK, Papadopoulos K, Fong PC, et al. A first-in-human, firstin-class, phase I study of carlumab (CNTO 888), a human monoclonal antibody against CC-chemokine ligand 2 in patients with solid tumors. Cancer Chemother Pharmacol. 2013;71(4):1041-1050.

76. Infante JR, Bendell JC, Goff LW, et al. Safety, pharmacokinetics and pharmacodynamics of the anti-A33 fully-human monoclonal antibody, KRN330, in patients with advanced colorectal cancer. Eur J Cancer. 2013;49(6):1169-1175.

77. Vugmeyster Y, Rohde C, Perreault M, Gimeno RE, Singh P. Agonistic TAM-163 antibody targeting tyrosine kinase receptor-B: applying mechanistic modeling to enable preclinical to clinical translation and guide clinical trial design. MAbs. 2013;5(3):373-383.

78. Reilly M, Miller RM, Thomson MH, et al. Randomized, double-blind, placebo-controlled, dose-escalating phase I, healthy subjects study of intravenous OPN-305, a humanized anti-TLR2 antibody. Clin Pharmacol Ther. 2013;94(5):593-600.

79. Zhu AX, Gold PJ, El-Khoueiry AB, et al. First-in-man phase I study of GC33, a novel recombinant humanized antibody against glypican-3, in patients with advanced hepatocellular carcinoma. Clin Cancer Res. 2013;19(4):920-928
Drug Design, Development and Therapy

\section{Publish your work in this journal}

Drug Design, Development and Therapy is an international, peerreviewed open-access journal that spans the spectrum of drug design and development through to clinical applications. Clinical outcomes, patient safety, and programs for the development and effective, safe, and sustained use of medicines are the features of the journal, which

\section{Dovepress}

has also been accepted for indexing on PubMed Central. The manuscript management system is completely online and includes a very quick and fair peer-review system, which is all easy to use. Visit http://www.dovepress.com/testimonials.php to read real quotes from published authors. 